\title{
Therapeutic competencies in reducing emotional and social distress after cognitive behavior therapy training program:
}

Three years follow up

\section{Zixi Elsayed Ibrahim. Abdelmohsen Ibrahim Daigham . ${ }^{1}$ zss11@fayoum.edu.eg}

\begin{abstract}
:
The aim of the study:

This paper addresses the question: is a brief cognitive behavior therapy (CBT) training program enhances psychologist's skills as reflected in scores on Cognitive Therapy Skills scale and in helping students with emotional and social problems.

\section{Materials and Methods:}

Participants are 35 school psychologists (20 Female and 15 male) have received intensive CBT training for 6 days during two weeks followed by one to one supervision in school sittings for three months. Participants completed cognitive behavior therapy scale (CBTS). Individual and group counseling sessions delivered to male and female (age mean $=13.7$ years) students known of emotional and social problems during the current school year. Supervisors wrote a report in the end of three months practice, students and parent's feedback had collected.
\end{abstract}

1) Associate Professor, Department of Psychology, Faculty of Arts, Minia University, Minia, Egypt. 
Results show that differences between pre and post scores on CBTS scale are statistically significant $(\mathrm{t}=4.92)$, supervisors reports and students feedback indicate improving therapeutic skills by the end of three months practice.

Conclusion: CBT training program has positive influence in enhancing CBT skills in school psychologists that reflected in providing effective counseling for students with emotional and social problems. Supervision based training optimizing the therapeutic outcome in both individual and group therapy sessions. Follow up of 3 years revealed continuous effect of the training and continuous supervision in improving counseling skills of school psychologists.

Key words: Cognitive behavior therapy (CBT), emotional problems, social problems, CBT skills, Cognitive therapy scale (CTS)

\section{Introduction}

Psychological services in the governmental schools face many challenges, since it established in (1990) side to side with the social services (Abousrea, Shawky, Anwar and Ismael.2009; Sherefeen \& Abouhasona, 2011). School psychologist's jobs were limited to behavioral assessment of emotional and academic problems (Ismael, 2006). School psychologists are willing to offer better job by applying the counseling and therapeutic change with students who suffered because of emotional, interpersonal, or academic 
problems (Yousef, 2009). One of the barriers to achieve this goal is preparing the school psychologists to be competent in delivering a professional help with these problems (Elfeky, 1990; Taha, 1990; Albana, 1990 \& kamel 1990; Ismael, 2006 ;Yousef, 2009).

Psychotherapeutic competence is conceptualized as a therapist's general and treatment-specific knowledge level, skill level, and values or attitudes while implementing therapeutic interventions (Kühne, Meister, Maaß, Paunov, \& Weck, 2019). Assessment of psychotherapeutic competences are essential to training, supervision, clients care, quality control, and life-long practice (Kühne, F., Lacki, F. J., Muse, K., \& Weck, F.,2019). Assessment of therapeutic competence may provide therapists with formative and summative feedback and may guide self-reflection (Muse and McManus 2013).

Cognitive behavior therapy (CBT) have been consistently shown to be effective across a wide range of disorders (Hofmann, Asnaani, Vonk, Sawyer, \& Fang, 2012; SKobori, Nakazato, Yoshinaga, Shiraishi, Takaoka, Nakagawa, \& Shimizu, 2014; Ho, Chan, \& Tang, 2016). Previous CBT training evaluations indicate that trainees' clinical competence and knowledge improve over the 
training period (McManus, Westbrook, Vazquez - Montes, Fennell, \& Kennerley, 2010). Measurement of cognitive behavioral therapy (CBT) competency is designed to reveal how well therapists deliver CBT, the results of which can serve many important functions in research and clinical training contexts and has the potential to optimize training and dissemination of CBT (Rozek, Serrano, Marriott, Scott, Hickman, Brothers, ... \& Simons, 2018). Cognitive Therapy Scale developed by Young and Beck in 1980 for assessing CBT skills (CTS; Young and Beck, 1980). It is the most established measurement of therapist competence in the context of providing CBT (Weck, Jakob, Neng, Höfling, Grikscheit, \& Bohus, 2016)

The aim of the study: This study is interested in investigating how far brief cognitive therapy training could enhance school psychologists CBT skills and offer better help for students known with emotional and social problems. School psychologists are capable to help students with their psychological problems, as they spend relatively long time with them and know about their strengths and weaknesses as well. Adjustment in school environment is very important and has a great impact on student's overall adjustment and psychological health. Cognitive behavior therapy is known 
as an effective treatment for many of the psychological problems (Beck, 1993, Beck, 1997, Beck 2005, Beck, Baruch, Balter, Steer,\& Warman, 2005). but results depend on the therapists' skill and competences (Kazantzis, Clayton, Cronin, Farchione, Limburg, \& Dobson, 2018). Training could enhance cognitive behavior therapy skills and enable those psychologists to help students to cope with their emotional and interpersonal problems. Supervision is essential in learning cognitive behavior therapy. Despite the divergence in systems of psychotherapy, their goals and varied training practices, supervision remains the one component considered essential to all (O'Donovan, Halford, \& Walters, 2011). Miller's (1990) hierarchical framework for assessing clinical skill, ranging from therapists' knowledge of CBT ('knows'), their practical understanding ('knows how'), their skill within artificial clinical simulations ('shows how'), and their skill within real clinical practice settings ('does') (Muse, McManus, Rakovshik, \& Thwaites, 2017). In his definition of supervision Milne (2009) stated that:

"The formal provision, by approved supervisors, of a relationship-based education and training that is workfocused and which manages, supports, develops and 
evaluates the work of colleague/s (precision). It therefore differs from related activities, such as mentoring and therapy, by incorporating an evaluative component (precision by differentiation) and by being obligatory. The main methods that supervisors use are corrective feedback on the supervisees' performance, teaching, and collaborative goal-setting (specification). The objectives of supervision are 'normative' (e.g. case management and quality control issues), 'restorative'(e.g. encouraging emotional experiencing and processing) and 'formative' (e.g. maintaining and facilitating the supervisees' competence" (Milne, 2009).

There is a growing body of literature showing that therapists receiving supervision have more positive clients' outcomes in therapy (O'Donovan, Halford, \& Walters, 2011).

The importance of this study in one aspect is that, helping the psychologists to enhance their professional skills in counseling and therapy services. On other aspects it enables testing the actual results of the training in real life sittings within schools. By giving them the opportunities to refine their counseling skills under a close extended supervision and evaluation of client's outcome from various perspectives. 
Few studies have examined multiple perspectives (i.e. independent observer, supervisor, trainee therapists and patient) of competency evaluation and few studies have examined all perspectives together. (Rozek, Serrano, Marriott, Scott, Hickman, Brothers, ... \& Simons, 2018).

Current study collects data from supervisors, students, teachers and parents, Which enables considering multiple feedback of therapy outcome.

\section{Material and Methods}

\section{Participants and supervisors:}

School psychologists of total number "35", (20 female and 15 male) with mean age of 31.7 years, average of 5.4 years of experience. Table (1) show participants' characteristics.

\section{Table (1) participant's demographic data}

\begin{tabular}{|l|l|}
\hline Total & 35 \\
\hline participants & $\begin{array}{l}15 \text { male, } \\
20 \text { female }\end{array}$ \\
\hline Age mean & 31.7 \\
\hline Experience years mean & 5.4 \\
\hline qualifications & $\begin{array}{l}\mathrm{Ba}(\mathrm{n}=31), \\
\operatorname{master}(\mathrm{n}=2), \\
\mathrm{PhD}(\mathrm{n}=2)\end{array}$ \\
\hline
\end{tabular}




\section{Supervisors}

Two Supervisors participated in the current study is a clinical psychologists (trained in CBT). Supervisor has served as trainers in psychotherapy training for 7 , and 17 years. Supervisor (1) had 12 years of clinical experience and school counseling. He got his Ph.D. in counseling and psychological wellbeing. Supervisor (2) had 23 years of clinical experience and academic teaching of clinical psychology.

\section{Measures:}

\section{Cognitive Therapy Scale (CTS):}

The Cognitive Therapy Scale (CTS) was developed by Young and Beck (1980), and modified by Blackburn and colleagues (Blackburn, James, Milne, \& Reichelt, 2001; James, Blackburn, \& Reichelt, 2001). An Egyptian version of the CTS validated by Sabra (2017), contains 11 items that evaluate specific aspects of therapist competence including agenda setting, dealing with problems/questions/objections, clarity of communication, pacing and efficient use of time, interpersonal effectiveness, resource activation, reviewing previously set homework, using feedback and summaries, guided discovery, focusing on central cognitions and behaviors, rationale, selecting appropriate strategies, appropriate implementation of techniques and assigning 
homework. The CTS uses a 7-point rating scale format, where $0=$ poor, $1=$ barely adequate, $2=$ mediocre, $3=$ satisfactory, $4=$ good, $5=$ very good and $6=$ excellent.

In the current study, the inter-rater reliability of the CTS mean scores between the two raters was high (0.87)

\section{COGNITIVE BEHAVIOR THERAPY SKILLS}

SCALE(CBTS) (Sabra, 2017), consists of 40 items with 5 points likert rating scale of $1=$ not use it at all to $5=$ use it most of the times. Alpha reliability is $0.92,(n=55)$ and test retest reliability is $0.74(n=20)$ with good validity indicators .(Sabra, 2017)

\section{Student's feedback:}

- Feedback after each session and behavioral observation of class mates included in sessions report that reviewed by supervisors.

\section{Supervising reports:}

Supervision is an educational process and, as such, benefits from using well-established principles that are known (from other contexts) to improve the likelihood of learning (Watkins,\& Milne, 2014, p.26)

- Written reports of psychological counseling sessions as a part of psychological activity plans during school 
year. The reports include activity plan, intervention tools and evaluation notes.

- Supervisors tasks is to help implementing and to evaluate the following items:

- Agenda Setting: Suitable items, feasible agenda

- CBT Interventions: Appropriate intervention targets, Choosing suitable interventions, Rationale for interventions, implementing interventions.

- Homework: Choosing suitable homework, Reviewing homework, Rationale for homework, planning homework.

- Assessing change: Choosing suitable measures.

- Effective Two-way Communication: Empathic understanding, Collaboration, Client feedback, Reflective summaries.

\section{Procedures}

Participants attend 6 days training in cognitive behavior therapy. The training included basics and techniques of cognitive behavior therapy of Adolescents problems. Participants completed Cognitive Behavior Therapy Skills Scale before and after the training course.

A close supervision is established for the first stage implementation in eleven preparatory schools. General 
psycho educational plan for students of these schools have been set, and individual counseling for students with emotional and interpersonal problems conducted too.

Feedback from students who received individual and group CBT counseling sessions for emotional and interpersonal problems collected. Other teachers and parent's feedback about those students' behaviors collected too. Supervisors reports collected by the end of each 3 months.

Follow up during 36 months to evaluate and enhance the counseling service in the Beni Mazar district primary schools.

\section{Results}

CBT training program has positive influence in enhancing CBT skills in school psychologists that reflected:

- Results of t-test of paired samples, of cbtss scores show that there is significant differences between pre and post mean scores as shown in (table $2 \& 3$ )

\section{Table 2}

Paired Sample Statistics

\begin{tabular}{|l|l|l|l|l|}
\hline CBTSS & M & N & SD & SEM \\
\hline CBTSS post & 168.85 & 33 & 27.373 & 5.211 \\
\hline CBTSS pre & 157.76 & 33 & 29.933 & 4.765 \\
\hline
\end{tabular}

Note. CBTSS post - scores on cognitive behavioral therapy skills scale after training; CBTSS pre - scores on cognitive behavioral therapy skills scale before training; $M$ - the mean (average); $S D$ - the standard deviation; SEM-the standard error of the mean 


\section{Table 3}

Results of Paired Sample T-Test ( $n=33$ )

\begin{tabular}{lllllll}
\hline \multirow{2}{*}{ CBTSS } & \multicolumn{2}{l}{ Paired differences } & \multirow{2}{*}{ DF } & \multirow{2}{*}{ Sig. } \\
\cline { 2 - 5 } & $M$ & SD & SEM & & & \\
\hline Pair 1, & 11.091 & 12.93 & 2.251 & 4.927 & 32 & 0.000 \\
CBTSS & & & & & & \\
post \& & & & & & & \\
CBTSS pre & & & & & & \\
\hline
\end{tabular}

Note. CBTSS post - scores on cognitive behavioral therapy skills scale after training; CBTSS pre - scores on cognitive behavioral therapy skills scale before training; $M$ - the mean (average); $S D$ - the standard deviation; SEM -the standard error of the mean; $T$ - the t-test statistic; $D F$ - the degrees of freedom; Sig. - significance level.

- providing effective counseling for students with emotional and interpersonal problems as indicated of reporting that :

○ reduced complaints of student's problematic behaviors

$O$ increasing involvement in counseling activities and sessions

O Parents reports show that kids became able to listen and conduct calmer communication between each other's.

○ Kids became more comfortable communicating with teachers and adults in their social network.

○ Kids are more motivated to participate in school activities and more likely to follow school rules 
- Supervision helped in optimizing the therapeutic outcome in both individual and group therapy sessions.

- after 3 years of follow up, supervisor report show that, psychological counseling became an established process in school year activity plan

- more schools became included in cbt counseling systematically. Psychologists became more familiar with cbt structure and use it in their routine counseling work with students.

- Efforts to communicate with students and their families during pandemic are continuing to help students cope with educational and evaluation method change since March 22020.

- Psychologists participated in enhancing awareness and protection of COVID-19 for students and their families.

- Psychologists provide brief useful psych education on anxiety symptoms that are widely spread during pandemic time through telehealth techniques.

- In the beginning of the 2018-2019 school year total of 105 school psychologist finished the cognitive behavior therapy training and were ready to establish 
the cognitive therapy and positive thinking program in all preparatory schools in BeniMazar district.

- The cognitive therapy and positive thinking program considered as a standard psychological activity program to be repeated each semester during the time between September 2018- March 2020.

\section{Research limitations and recommendations for future studies:}

- data collection in this research focused on client out come and supervisors reports. Need for collecting data on supervisees' competence, that include supervisors systematically sampling supervisees' in-session behaviour. as O'Donovan and collages recommended. O'Donovan, A., Halford, W. K., \& Walters, B. (2011).

- Future research should continue to work on validating and refining competency measures in order to enhance training and, allowing for better clients outcomes.

- future studies needed to replicate these findings with a larger sample and a wider variety of counselor's experience.

- more tools are needed to improve tele-counseling processes. 


\section{Acknowledgements}

We would like to express our deepest gratitude to Dr. Ahmed Gamal Alshereef, for his efforts in organizing and supervising activities during the program and the following 3 year while the CBT counseling was delivering to students at schools. 


\section{References}

- Abousrea,O.; Shawky, M.; Anwar,A. \& Ismael. S. (2009). Life skills program for enriching the scholastic environment, Guide for senior school psychologists, In: Research and studies in psychology (Memorial book). Cairo University, Faculty of Arts press, 311-350

- Albana, K. (1990). Therapeutic duties of psychologists in Egypt. IN: Forum for Scientific and Practical Preparing Psychologists in Egypt, Technological Development and Planning Institute, Cairo University

- Beck, A. (1967). Depression: Clinical, experimental, and theoretical aspects. University of Pennsylvania Press.

- Beck, A.T, (1976). Cognitive Therapy and the Emotional Disorders. New York: A meridian book.

- Beck, Aaron T.; Rush, A. John; Shaw, Brian F.; Emery, G. (1979). Cognitive Therapy of Depression.new york: Guilford Press

- Beck, A. T., (1991). Cognitive therapy: A 30 - year Retrospective, American Psychologist, vol 46 (4), P.P. $368-375$.

- Beck, A. T. (1993). Cognitive therapy: past, present, and future. Journal of consulting and clinical psychology, 61(2), 194.

- Beck, A. T. (1997). The past and future of cognitive therapy. The Journal of psychotherapy practice and 
research, 6(4), 276.

- Beck, A. T. (2005). The current state of cognitive therapy: a 40-year retrospective. Archives of General Psychiatry, 62(9), 953-959.

- Beck, A. T., Baruch, E., Balter, J. M., Steer, R. A.,\& Warman, D. M. (2004). A new instrument for measuring insight: the Beck Cognitive Insight Scale. Schizophrenia research, 68(2), 319-329.

- Beck, J. S. (1995). Cognitive therapy: Basics and beyond. New York: Guilford.

- Blackburn, I. M., James, I. A., Milne, D. L., Baker, C., Standart, S., Garland, A., \& Reichelt, F. K. (2001). The revised cognitive therapy scale (CTS-R): psychometric properties. Behavioural and cognitive psychotherapy, 29(4), 431-446.

- Clark, D.A., Beck A.T.\& Alford, B.A. (1999) Scientific Foundations of Cognitive Theory and Therapy, New York : John wiley\& sons.

- Elfeky, I. (1990) Roles of the school psychologist. IN: Forum for Scientific and Practical Preparing Psychologists in Egypt, Technological Development and Planning Institute, Cairo University.

- Ho, F. Y., Chan, C. S., \& Tang, K. N. (2016). Cognitive

- behavioral therapy for sleep disturbances in treating posttraumatic stress disorder symptoms: A meta - analysis 
of randomized controlled trials. Clinical Psychology Review, 43(October), 90-102. https://doi.org/10.1016/j.cpr.2015.09.005

- Hofmann, S. G., Asnaani, A., Vonk, I. J. J., Sawyer, A. T., \& Fang, A. (2012, October 31). The efficacy of cognitive behavioral therapy: A review of meta - analyses. Cognitive Therapy and Research. Springer US. https://doi.org/10.1007/s 10608 - 012 - 9476 - 1

- Ismael, S. (2006). Obstacles that face Profession of psychology in Egypt. Annual book of Faculty of ArtsCairo Uni versity, Cairo University press, 533-606.

- James, I. A., Blackburn, I. M., \& Reichelt, F. K. (2001). Manual of the revised cognitive therapy scale. Unpublished manuscript, Newcastle Cognitive and Behavioural Therapies Centre, Newcastle, UK

- kamel, A. (1990). Academic and occupational Foundations for preparing psychologists. IN: Forum for Scientific and Practical Preparing Psychologists in Egypt, Technological Development and Planning Institute, Cairo University

- Kazantzis, N., Clayton, X., Cronin, T. J., Farchione, D., Limburg, K., \& Dobson, K. S. (2018). The Cognitive Therapy Scale and Cognitive Therapy Scale-Revised as measures of therapist competence in cognitive behavior therapy for depression: Relations with short and long term 
outcome. Cognitive Therapy and Research,42(4), 385397.

- Kobori, O., Nakazato, M., Yoshinaga, N., Shiraishi, T., Takaoka, K., Nakagawa, A., ... \& Shimizu, E. (2014). Transporting Cognitive Behavioral Therapy (CBT) and the Improving Access to Psychological Therapies (IAPT) project to Japan: preliminary observations and service evaluation in Chiba.The Journal of Mental Health Training, Education and Practice.. 9 (3), 155-166.

- Kühne, F., Lacki, F. J., Muse, K., \& Weck, F. (2019). Strengthening competence of therapists-in-training in the treatment of health anxiety (hypochondriasis): V alidation of the A ssessment of C ore CBT S kills (ACCS). Clinical psychology \& psychotherapy, 26 (3), 319-327.

- Kühne, F., Meister, R., Maaß, U., Paunov, T., \& Weck, F. (2019). How Reliable Are Therapeutic Competence Ratings? Results of a Systematic Review and MetaAnalysis. Cognitive Therapy and Research, Nov. 1-17. https://doi.org/10.1007/s10608-019-10056-5

- McManus, F., Westbrook, D., Vazquez - Montes, M., Fennell, M., \& Kennerley, H. (2010). An evaluation of the effectiveness of Diploma - level training in cognitive behaviour therapy. Behaviour Research and Therapy, 48(11), 1123-1132. https://doi.org/10.1016/j.brat.2010.08.002 
- Milne, D. (2009). Evidence-based clinical supervision. Principles and practice. Chichester, UK: BPS Blackwell.

- Muse, K., \& McManus, F. (2013). A systematic review of methods for assessing competence in cognitive behavioural therapy. Clinical Psychology Review, 33(3), 484-499. https://doi.org/10.1016/j.cpr.2013.01.010

- Muse, K., McManus, F., Rakovshik, S., \& Thwaites, R. (2017). Development and psychometric evaluation of the Assessment of Core CBT Skills (ACCS): An observationbased tool for assessing cognitive behavioral therapy competence. Psychological Assessment, 29(5), 542555. https://doi.org/10.1037/pas0000372

- O'Donovan, A., Halford, W. K., \& Walters, B. (2011). Towards best practice supervision of clinical psychology trainees. Australian Psychologist, 46(2), 101-112.

- Pilling,S., Roth, A.D. (2014). The Competent Clinical Supervisor, In: Watkins Jr, C. E., \& Milne, D. L. (Eds.). The Wiley international handbook of clinical supervision. John Wiley \& Sons(pp.20-37).

- Rozek, D. C., Serrano, J. L., Marriott, B. R., Scott, K. S., Hickman, L. B., Brothers, B. M., ... \& Simons, A. D. (2018). Cognitive behavioural therapy competency: Pilot data from a comparison of multiple 
perspectives. Behavioural

and

cognitive psychotherapy, 46(2), 244-250.

- Sabra, Z.I. (2017). Cognitive Behavioral therapy skills in profession and daily life contexts, Psychological studies, 38 (1), 25-93.

- Sherefeen, A. \& Abouhasona, N. (2011). Factors that predict Professional motivation in Counseling psychology' students at Jordanian Universities, Faculty of Education Journal, 35(1), 127-164.

- Taha,F. (1990). Toward an Impetuous Academic program for preparing psychologists in Egyptian Universities, IN: Forum for Scientific and Practical Preparing Psychologists in Egypt, Technological Development and Planning Institute, Cairo University.

- Weck, F., Jakob, M., Neng, J. M., Höfling, V., Grikscheit, F., \& Bohus, M. (2016). The effects of bug-inthe-eye supervision on therapeutic alliance and therapist competence in cognitive-behavioural therapy: A randomized controlled trial. Clinical psychology \& psychotherapy, 23(5), 386-396.

- Young, J., \& Beck, a. (1980). Cognitive Therapy Rating Scale (CTRS), 4-7. Retrieved from info@beckinstitute.org

- Young, J., \& Beck, A. T. (1980). Cognitive therapy 
scale: Rating manual. Unpublished manuscript, 36th.

- Yousef, G. S. (2009). Contributions of psychologists in practice of Cognitive Behavioral Therapy (exploratory study). In: Research and studies in psychology (Memorial book). Cairo University, Faculty of Arts press, 27-49. 